\title{
LEITURA DE UM TEXTO DE SIMMEL À LUZ DE ASPECTOS DE SUA TRAJETÓRIA INTELECTUAL
}

O "excurso sobre o problema: como é possível a sociedade?" veio primeiro a público em I908, como parte da Soziologie - a chamada "grande" sociologia de Georg Simmel (I858-I9I8). Trata-se, para ser mais exato, do excurso ao primeiro capítulo do livro, capítulo este que possui uma posição estratégica na economia retórica da obra: é ao longo dele que Simmel expõe o que entende por sociologia, visando uma delimitação precisa do campo de atuação dessa que era, em seu tempo, uma forma emergente de conhecimento.

O excurso em questão se destaca do resto do livro por ser um dos poucos trechos realmente inéditos da Sociologia - composta, em grande medida, pela reunião de ensaios, artigos e até mesmo capítulos extraídos de outros livros de sua autoria, publicados ao longo das décadas de I89o e I900. É não só um trabalho de maturidade, mas também, por seu teor, um texto especial na trajetória de Simmel enquanto sociólogo. Isso porque o registro aí empregado por Simmel para tratar de problemas básicos da teoria social difere bastante do que ele usualmente empregava para esse fim. Comparando outros textos mais "teóricos" de Simmel - publicados entre i890 e I9I7 -, ${ }^{\text {I }}$ vemos que, apesar das diferenças de ênfase e conteúdo de um texto a outro, há grande homogeneidade entre eles: tratava-se, nesses casos, de situar a sociologia face a outras formas de conhecimento, de indicar seus problemas, conceitos e procedimentos básicos. Não é bem isso que vemos no texto ora apresentado. Nele, não temos mais um programa para uma nova ciência, 
mas uma real investigação das condições de existência de seu objeto. Daí que Simmel tenha encaixado esse texto em particular como um excurso ao primeiro capítulo da Sociologia.

A estratégia expositiva do texto também é outra (lembra menos seus outros textos sobre sociologia, e mais seus trabalhos sobre a filosofia da história). Simmel propõe aqui, para a sociedade, uma questão análoga à que Kant propusera para a natureza: como ela é possível? Ou seja: que condições têm de estar dadas a priori para que se possa verificar certa realidade? - no caso, isso que Simmel chama de "sociedade empírica". O texto é marcado, do começo ao fim, por uma cadeia de analogias positivas e negativas entre, de um lado, a unidade da natureza segundo Kant - e Simmel dialogava, aqui, sobretudo com o Kant da Crítica da razão pura e dos Prolegômenos - e, de outro, a unidade ou síntese em que as formas de socialização se engendram.

Devemos estar atentos para que o Simmel do final da década de I900 - portanto, aquele que escreveu o texto aqui apresentado - se inclinava cada vez mais para o vitalismo e para a filosofia da arte, algo visível em alguns trechos do texto. Nesse sentido, pode-se dizer que temos aqui um trabalho sobre teoria social escrito por alguém que, a essa altura de sua vida, identifica-se, sobretudo, como filósofo. Isso de um lado. Pois, de outro, o Simmel de I908 reflete sobre teoria social após ter dedicado pelo menos uma década e meia de sua vida à sociologia. O livro de que o excurso foi tirado representa, afinal, a execução de um projeto apresentado pela primeira vez de forma mais clara em 1894, mas que já se desenhava na cabeça de Simmel desde antes. Nesse sentido, trata-se de um texto escrito por alguém que, embora se identifique como filósofo, já está habituado a pensar como sociólogo. Esse fato se desdobra em toda uma série de articulações entre esse texto e outros trechos da Sociologia - como os capítulos 5, 6 e Io (nesta ordem: sobre o segredo; o cruzamento dos círculos sociais; e a correlação entre a ampliação do grupo e a formação da individualidade) e as inúmeras referências espalhadas ao longo do livro a tipos sociais, das quais é possível destacar todo o capítulo 7, sobre o "pobre", e os excursos sobre a nobreza e o estranho (ver Tyrell, 2007: 33-36).

Parte dessas temáticas - inclusive as que mais tarde fariam a fama de Simmel como fundador da microssociologia, como o segredo, o adorno, a carta etc. - foram trabalhadas intensamente por Simmel entre os anos de I905 e I908 (ver Simmel, I992b: 876-877), portanto sob o impacto de seu livro sobre Kant, publicado em I904, e da segunda edição d'Os problemas da filosofia da história, de I905. A linguagem francamente kantiana mobilizada no excurso ora apresentada pode, em parte, ser atribuída a esse impacto. Mas deixemos Kant de lado por enquanto, e nos concentremos nos Problemas da filosofia da história, em sua relação com os da sociologia. Em I908, Simmel propõe, para a sociologia, uma pergunta análoga à que ele, seguindo Kant, há três anos 
propusera para a história (como ela é possível?). Tal pergunta, não formulada na primeira edição do livro sobre a filosofia da história, faz parte de uma série de outros reajustes com os quais Simmel buscou remendar as insuficiências que ele próprio detectara em seus trabalhos de juventude - que ele veria como deficiências passíveis de correção após publicar sua Philosophie des Geldes [Filosofia do dinheiro]. Essa obra marca sua trajetória intelectual em muitos sentidos: não só é diante dela que Simmel percebe a necessidade de reescrever sua filosofia da história (ver Simmel, 2008: 47I), como mesmo seu crescente interesse em estudar as formas mais efêmeras de socialização - que, quando jovem, ele considerou "intratáveis" por uma sociologia científica² - é, em parte, um desdobramento do estilo filosófico ali desenvolvido, que consiste em capturar o universal no particular (ver Waizbort, 2000: 92-99).

Feita essa colocação, é hora de, ao modo dos alemães no tempo de Simmel, voltarmos a Kant. Do fato de Simmel se apoiar em Kant não devemos concluir que o siga à risca, isto porque, como mostrei alhures (Bárbara, 2012: 248-25I), a referência a Kant faz mais sentido se compreendida como uma estratégia visando conferir à sua empreitada sociológica maior credibilidade e rigor. Afinal, o domínio da linguagem kantiana era um trunfo considerável no contexto intelectual em que Simmel estava inserido. Ele, claro, apropria-se dessa linguagem para dizer algo para o qual ela não fora, de início, forjada, adaptando-a para que pudesse apreender em conceitos o social - e contribuindo, assim, para a invenção da sociologia.

Por trás da linguagem kantiana, por vezes bastante árida, que marca o texto seguinte, temos no fundo um ensaio simmeliano - ele mesmo, aliás, concebe tais investigações como esboços exemplares para uma epistemologia das ciências da sociedade, ou seja, não pretende aí esgotá-la. Daí que ele deva ser lido como um ensaio sobre temas da teoria social.

Esses são apenas apontamentos muitíssimo gerais sobre o texto, visando fornecer um mínimo de elementos para que o leitor possa situá-lo no contexto da trajetória intelectual de Simmel. Convém acrescentar uma nota sobre algumas das traduções até então disponíveis. A primeira delas foi publicada apenas dois anos após a Soziologie, com tradução de Albion Small, importante irradiador da obra de Simmel nos EUA. Em português, o texto seria publicado em I969, sob o título (ausente no original) "Requisitos universais e axiomáticos da sociedade". Trata-se de uma versão da tradução espanhola da Soziologie, esta feita por José R. Pérez-Bances (ver Simmel, I998, V. I), e primeiro publicada em seis volumes, entre I926-I927. Essa versão brasileira, atualmente fora de catálogo, baseia-se na segunda edição da tradução de Pérez-Bances. 
LEITURA DE UM TEXTO DE SIMMEL À LUZ DE ASPECTOS DE SUA TRAJETÓRIA INTELECTUAL

648

A presente tradução foi feita diretamente a partir do texto de Simmel, e com sua publicação se pretende divulgar e fixar, entre nós, uma visão mais ampla da sociologia que esse clássico não apenas praticou com excelência, como também ajudou a inventar.

Recebido em 02/02/2013 | Aprovado em 10/05/2013

Lenin Bicudo Bárbara é mestre em Sociologia pela Universidade de São Paulo (USP), onde também se graduou em Ciências Sociais. Em seu mestrado, investigou o papel exercido pelo procedimento analógico na teoria social e na teoria do conhecimento de Simmel. 


\section{NOTAS}

I Ver, além do resto do já mencionado primeiro capítulo da Soziologie (disponível em português, sem o excurso, em Moraes Filho, I983: 59-78), o capítulo introdutório de Über sociale Differenzierung [Sobre a diferenciação social], originalmente publicado em I89o (Simmel, I989b: II5-I38); o artigo programático de 1894 , a que Simmel deu o mesmo título que daria ao primeiro capítulo da Soziologie, a saber: "Das Problem der Sociologie" [O problema da sociologia] (ver Simmel, I992a; disponível em inglês em Simmel, I994); e também o capítulo introdutório das "Grundfragen der Soziologie" ["Questões fundamentais da sociologia"], a "pequena" sociologia, de I9I7 (ver Simmel, I999; ou, em português, Simmel, 2006; e Moraes Filho, I983: 79-86). Para uma abordagem comparada de alguns desses trabalhos, ver Frisby (1994); bem como o terceiro capítulo de minha dissertação de mestrado (Bárbara, 20I2) - em que, contudo, a comparação é do começo ao fim pautada pela análise das analogias que Simmel formulou nesses textos.

2 Simmel assimilaria tais fenômenos à sociologia só pouco antes da publicação da Soziologie - antes, ele, via de regra, os referia à psicologia ou à psicologia social (embora seu conceito de socialização já fosse, desde muito cedo, compatível com a abordagem microssociológica). Sobre a posição do jovem Simmel a respeito, ver Simmel (I989b: I33-I34). Traduzi essa passagem e comentei o ponto em minha dissertação (Bárbara, 2012: 234).

\section{REFERÊNCIAS BIBLIOGRÁFICAS}

Bárbara, Lenin Bicudo. (2012). Simmel e a analogia: investigações sobre o uso e os aspectos epistemológicos da analogia na Soziologie e na Philosophie des Geldes de Georg Simmel. Dissertação de mestrado. PPGS/Universidade de São Paulo.

Frisby, David. (1994). The foundation of sociology. In: Georg Simmel: critical assessments. Londres/Nova York: Routledge, v. I, p. 329-346.

Moraes Filho, Evaristo de (org). (1983). Georg Simmel: sociologia. São Paulo: Ática.

Simmel, Georg. (I9Io). How is society possible? American Journal of Sociology, XVI/ 3, p. 372-39I. 
Simmel, Georg. (1969). Requisitos universais e axiomáticos da sociedade. In: Fernandes, Florestan (org.). Comunidade e sociedade: leituras sobre problemas conceituais, metodológicos e de aplicação. São Paulo: Companhia Editora Nacional/ Edusp, p. 62-8I.

Simmel, Georg. (2008). Briefe: Band I (Georg Simmel Gesamtausgabe, v. 22). Frankfurt am Main: Surhkamp.

Simmel, Georg. (2006). O âmbito da sociologia. In: Questões fundamentais da sociologia. Rio de Janeiro: Zahar, p. 7-38.

Simmel, Georg. (1999). Das Gebiet der Soziologie. In: Grundfragen der Soziologie: Individuum und Gesellschaft (Georg Simmel Gesamtausgabe, v. I6). Frankfurt am Main: Surhkamp, p. 62-87.

Simmel, Georg. (1998). Sociología: estudios sobre las formas de socialización. Madrid: Alianza.

Simmel, Georg. (1997). Die Probleme der Geschichtsphilosophie: eine erkenntnistheoretische Studie (Georg Simmel Gesamtausgabe, v. 9). Frankfurt am Main: Surhkamp.

Simmel, Georg. (1994). The problem of sociology. In: Frisby, David (org.). Georg Simmel: critical assessments. Londres/ Nova York: Routledge, v. I, p. 28-35.

Simmel, Georg. (1992a). Das Problem der Sociologie. In.: Aufsätze und Abhandlungen I894-1900 (Georg Simmel Gesamtausgabe, v. 5). Frankfurt am Main: Surhkamp, p. 52-6I.

Simmel, Georg. (1992b). Soziologie: Untersuchungen über die Formen der Gesellschaftung (Georg Simmel Gesamtausgabe, v. II). Frankfurt am Main: Surhkamp.

Simmel, Georg. (1989a). Philosophie des Geldes (Georg Simmel Gesamtausgabe, v. 6). Frankfurt am Main: Surhkamp.

Simmel, Georg. (1989b). Aufsätze I887-I890 (Georg Simmel Gesamtausgabe, v. 2). Frankfurt am Main: Surhkamp.

Tyrell, Hartmann. (2007). Georg Simmel's „große“ Soziologie (1908): eine Überlegungen anläßlich des bevorstehenden Iоo. Geburtstags. In: Simmel Studies, XVII/I, p. 5-39. Waizbort, Leopoldo. (2000). As aventuras de Georg Simmel. São Paulo: Ed. 34. 
Palavras-chave

Georg Simmel;

Teoria social;

Epistemologia;

História da sociologia;

Neokantismo.

Keywords

Georg Simmel;

Social theory;

Epistemology;

History of sociology;

Neo-kantianism

\section{LEITURA DE UM TEXTO DE SIMMEL À LUZ} DE ASPECTOS DE SUA TRAJETÓRIA INTELECTUAL

\section{Resumo}

O presente artigo consiste numa brevíssima apresentação para a tradução de um texto do pensador alemão Georg Simmel. Ao longo de toda esta apresentação, assumo a premissa de que esse é um texto-chave para uma compreensão adequada da produção sociológica de Simmel. Meu objetivo aqui é situar - ainda que apenas de forma algo aproximada - esse texto em particular na trajetória intelectual de seu autor. Para tal, indico algumas relações cronológicas e temáticas entre esse e alguns dos outros textos que ele escreveu. Sugiro, a pretexto de conclusão, que o texto deve ser lido como um ensaio maduro sobre teoria social.

\section{A READING OF ONE OF SIMMEL'S WRITINGS IN LIGHT OF SOME ASPECTS OF HIS INTELLECTUALTRAJECTORY}

Abstract

This article comprises a very brief introduction to a Portuguese translation of a text by the German thinker Georg Simmel. For this introduction, I adopt the assumption that this is a key text to a due comprehension of Simmel's sociological accomplishments. I aim here to indicate - but only in rather a sketchy manner - the placement of such text along the lines of Simmel's intellectual trajectory. In order to do so, I point to some chronological and thematic relations between this text and some of the others he wrote. I propose, as a sort of conclusion, that the text should be read as a mature essay on social theory. 